$\S=-1$

\title{
Groundwater Quality Assessment in Ambattur Industrial Estate
}

\author{
D. Sivakumar ${ }^{1 *}$, S. Govindasami ${ }^{2}$, J. Asanammal Saral ${ }^{3}$, D. Arun ${ }^{4}$, T. Durai Arasu ${ }^{5}$ \\ 1,2,3,4,5 Department of Civil Engineering, \\ Vel Tech High Tech Dr.Rangarajan Dr.Sakunthala Engineering College, Avadi, Chennai, Tamil Nadu, India \\ *Corresponding author E-mail:shri.sivakumar1974@gmail.com
}

\begin{abstract}
Groundwater is generally used for various purposes, particularly domestic and industrial purposes in all over the world. Fresh water from groundwater sources is high in the recent years and the groundwater is polluted high because of rapid population and industrial growth. It is very difficult to restore the contaminated groundwater by various pollutants. Hence, it is important to analyse physico-chemical parameters of groundwater for its need for various sectors. Therefore, the present study was under taken to define the quality of groundwater with the help of WQI. The ground water samples were collected from 20 different places around Ambattur Industrial Estate in Chennai city. The groundwater quality assessment showed that the water quality of bore wells around Ambattur Industrial Estate is poor for drinking purpose as per WQI for BIS acceptable limit. WQI observed from those selected 20 groundwater bore wells are ranging from 63.30 to 219.63. The analysis reveals that the groundwater from the Ambattur Industrial Estate needs pre-treatment before it is being used for various purposes.
\end{abstract}

Keywords: Ambattur industrial estate; Physico-chemical parameters; Water quality index; BIS;

\section{Introduction}

Water is one of the basic needs for any living being survival that shapes other land and air environment. The water quality is important and influencing the health aspect of human being. The water sources are coming from both surface and below surface sources. The groundwater sources are particular for supplying water for domestic and industrial purposes. In conjunction with surface water, groundwater is supplied for irrigation purpose. The groundwater is polluted because of over population and industrial growth.

The most potent threats to the quality of groundwater that have emerged from India are pollution. Quality of groundwater is affecting due to presence of poor drainage system. The physicochemical characteristics of ground water are varying depends on the types of pollutants from water and wastewater sources.

Of all purposes, ground water should be more quality, hence, it is necessary to analyses the ground water quality before being used for domestic purposes. This can be done through Water Quality Index (WQI) assessment.

The GIS based assessment of groundwater quality with the help of WQI at Tirupathi, India was studied by Ambiga [1]. The groundwater quality of Dhrol taluka of Jamnagar district (India) was analyzed by Patel [2]. Furthermore, groundwater quality was assessed using index in Tumkur Taluk, Karnataka state, India by Ramakrishnaiah [3] and the WQI assessment of groundwater in Koilwar Block was determined by Neerja [4]. In addition the groundwater quality around Ampikapuram area of Tiruchirappalli District, Tamil Nadu, India was studied by Sirajudeen [5]. Groundwater quality around Pallavaram, Chennai, Tamil Nadu was determined for its suitability of drinking purpose by Sivakumar [6], and in and around Tannery industrial belt was assessed by Sivakumar [7], and checked the suitability of groundwater for irrigation in Pulicat Sivakumar [8], around Perungalathur [9] was studied. The correlation was done between the quality parameters around Perungalathur, also done by Sivakumar [10].

The purposes of the study are to find the physico-chemical characteristics and appropriateness of groundwater for domestic usage of Ambattur industrial estate. The objectives defined for this project are to identify the ground water pollution around Ambattur industrial estate, to study the appropriateness of groundwater for drinking with references to BIS standards and to verify the suitability of ground water using Water Quality Indices (WQI).

\section{Methods and Materials}

\subsection{Study Area}

Ambattur Industrial Estate is an industrial area located in Chennai. The total area in Ambattur Industrial Estate is 1300 acres with 1500 small and medium enterprises. Groundwater is mostly used for domestic and industrial purposes. Groundwater is polluted by discharge of large volume of wastewater from small and medium enterprises and dumping of solid wastes from those sectors. The map of selected area for the assessment of groundwater is shown in Fig.1.

\subsection{Collection of Groundwater Samples}

The parameters $\mathrm{pH}$, TDS, TH, Calcium, Magnesium, Sulphate, Nitrate, Total alkalinity, Chloride, Fluoride, Sodium, Bicarbonate and Potassium were analysed in the groundwater of bore well around Ambattur Industrial Estate. Groundwater samples were collected from 20 different bore wells. One litre capacity sterilized plastic bottles with proper washed have been used for collecting groundwater samples. The sterilized bottles were used to collect the groundwater. Latitude and Longitude of the sample collecting 
spots were recorded with the help of GPS reading. Each groundwater sample was analyzed against 13 parameters. The groundwater quality parameters of Ambattur Industrial Estate were compared with BIS. The calculation of WQI was done to discover the appropriateness of groundwater for drinking.

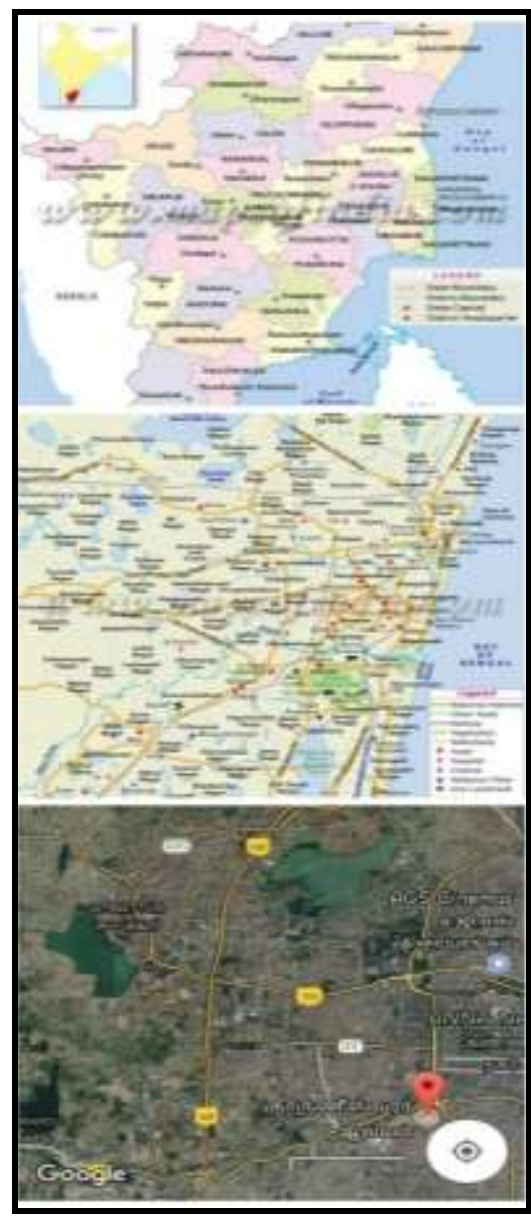

Fig. 1: Map of the Study Area

\subsection{Location of Wells}

The Table 1 represents the location of 20 groundwater sample station and the corresponding latitude and longitude of the selected bore wells is presented.

Table 1: Location of Wells

\begin{tabular}{|c|c|c|}
\hline Wells & Latitude & Longitude \\
\hline 1 & 13.118 & 80.204 \\
\hline 2 & 13.118 & 80.196 \\
\hline 3 & 13.096 & 80.174 \\
\hline 4 & 13.100 & 80.161 \\
\hline 5 & 13.111 & 80.170 \\
\hline 6 & 13.114 & 80.165 \\
\hline 7 & 13.106 & 80.164 \\
\hline 8 & 13.116 & 80.170 \\
\hline 9 & 13.105 & 80.170 \\
\hline 10 & 13.102 & 80.167 \\
\hline 11 & 13.102 & 80.171 \\
\hline 12 & 13.109 & 80.174 \\
\hline 13 & 13.114 & 80.177 \\
\hline 14 & 13.102 & 80.177 \\
\hline 15 & 13.105 & 80.180 \\
\hline 16 & 13.110 & 80.182 \\
\hline 17 & 13.113 & 80.184 \\
\hline 18 & 13.116 & 80.189 \\
\hline 19 & 13.108 & 80.187 \\
\hline 20 & 13.100 & 80.182 \\
\hline
\end{tabular}

\subsection{BIS Drinking Standard}

The standard was adopted by the Bureau of Indian Standard with the objectives for assessing and checking effectiveness of water treatment. Table 2 shows standard for drinking against accepted and permissible limit recommended by BIS.

Table 2: BIS standards

\begin{tabular}{|c|c|c|}
\hline Parameters & Acceptable Limit & Permissible Limit \\
\hline $\mathrm{pH}$ & 7 & 7.2 \\
\hline $\mathrm{Ca}$ & 75 & 200 \\
\hline $\mathrm{Mg}$ & 30 & 100 \\
\hline $\mathrm{Na}$ & 200 & 200 \\
\hline $\mathrm{K}$ & 10 & 10 \\
\hline $\mathrm{HCO}_{3}$ & 200 & 200 \\
\hline $\mathrm{SO}_{4}$ & 200 & 400 \\
\hline $\mathrm{Cl}^{\mathrm{NO}}$ & 250 & 1000 \\
\hline $\mathrm{F}$ & 45 & 100 \\
\hline $\mathrm{TDS}$ & 1 & 1.5 \\
\hline $\mathrm{TH}$ & 500 & 2000 \\
\hline $\mathrm{TA}$ & 300 & 600 \\
\hline & 200 & 600 \\
\hline
\end{tabular}

\subsection{Water Quality Index (WQI)}

Water quality is assessed with the help of WQI and it is determined as per below various steps.

First step: Based on the relative importance, assign the weight to each parameter (wi). The maximum weight factor is 5 and minimum is 1 . The one 5 is assigned to most important parameters and 1 is assigned to least important parameters, which influencing the strength of the contaminant in the groundwater.

Second step: Relative weight (Wi) is computed

$\mathrm{Wi}=\mathrm{wi} / \sum \mathrm{wi}$

Third step: A quality rating scale (qi) for each parameter is assigned:

$\mathrm{qi}=(\mathrm{Ci} / \mathrm{si}) \times 100$

where, qi $=$ quality rating, $\mathrm{Ci}=$ concentration of each parameter in $\mathrm{mg} / \mathrm{l}$, and $\mathrm{si}=$ water standard of each parameter in $\mathrm{mg} / \mathrm{l}$.

Fourth step: the product of Wi and qi is calculated ( $\mathrm{Si}$ ).

$\mathrm{Si}=\mathrm{Wi} \times \mathrm{qi}$

Fifth step: WQI is calculated as below.

$\mathrm{WQI}=\Sigma \mathrm{Si}$

The WQI standard ranges are presented in Table 3.

\begin{tabular}{|c|c|}
\hline \multicolumn{2}{|c|}{ Table 3: WQI standard ranges } \\
\hline WQI Value & Water Quality \\
\hline$<50$ & Excellent \\
\hline $50-100$ & Good \\
\hline $100-200$ & Poor \\
\hline $200-300$ & Very Poor \\
\hline$>300$ & Not fit for drinking \\
\hline
\end{tabular}

\section{Results and Discussion}

The parameters $\mathrm{pH}$, TDS, TH, Calcium, Magnesium, Sulphate, Nitrate, Total alkalinity, Chloride, Fluoride, Sodium, Bicarbonate and Potassium were analysed in the 20 groundwater of bore well around Ambattur Industrial Estate. The Table 4 represents the physico-chemical parameters of the collected groundwater samples from 20 sites. 
Table 4: Physico-chemical parameters of 20 bore well samples

\begin{tabular}{|c|c|c|c|c|c|c|c|c|c|c|c|c|c|}
\hline Wells & $\mathrm{pH}$ & $\mathrm{Ca}$ & $\mathrm{Mg}$ & $\mathrm{Na}$ & $\mathrm{K}$ & $\mathrm{HCO}_{3}$ & $\mathrm{SO}_{4}$ & Chloride & Nitrate & Fluoride & TDS & $\begin{array}{c}\mathrm{TH} \\
\left(\mathrm{CaCO}_{3}\right)\end{array}$ & $\begin{array}{c}\text { Total } \\
\text { Alkalinity }\end{array}$ \\
\hline 1 & 7.1 & 88 & 182 & 433 & 3 & 580 & 10 & 922 & 9 & 0.61 & 2032 & 970 & 475 \\
\hline 2 & 7.2 & 38 & 22 & 110 & 0 & 275 & 40 & 121 & 4 & 0.52 & 473 & 185 & 225 \\
\hline 4 & 7.2 & 36 & 75 & 366 & 0 & 531 & 314 & 248 & 9 & 1.58 & 1315 & 400 & 435 \\
\hline 5 & 6.4 & 148 & 126 & 478 & 28 & 366 & 148 & 1046 & 38 & 0.35 & 2195 & 890 & 300 \\
\hline 6 & 6.6 & 120 & 117 & 438 & 20 & 389 & 173 & 861 & 31 & 0.57 & 1956 & 780 & 318 \\
\hline 7 & 6.9 & 80 & 100 & 401 & 11 & 444 & 237 & 584 & 21 & 1 & 1656 & 612 & 364 \\
\hline 8 & 6.5 & 133 & 121 & 453 & 24 & 375 & 157 & 948 & 34 & 0.45 & 2059 & 831 & 307 \\
\hline 9 & 6.6 & 113 & 118 & 431 & 18 & 383 & 184 & 832 & 30 & 0.59 & 1918 & 767 & 314 \\
\hline 10 & 7 & 68 & 100 & 385 & 7 & 441 & 250 & 253 & 18 & 1 & 1574 & 581 & 361 \\
\hline 11 & 6.9 & 86 & 117 & 392 & 11 & 376 & 212 & 692 & 24 & 0.73 & 1722 & 696 & 308 \\
\hline 12 & 6.6 & 132 & 122 & 456 & 24 & 371 & 159 & 947 & 34 & 0.44 & 2057 & 833 & 304 \\
\hline 13 & 6.7 & 118 & 117 & 422 & 20 & 375 & 154 & 857 & 30 & 0.5 & 1908 & 775 & 308 \\
\hline 14 & 7 & 82 & 121 & 377 & 9 & 354 & 202 & 694 & 23 & 0.65 & 1687 & 703 & 290 \\
\hline 15 & 6.9 & 89 & 115 & 377 & 11 & 368 & 175 & 705 & 23 & 0.6 & 1681 & 696 & 301 \\
\hline 17 & 6.9 & 83 & 97 & 326 & 10 & 371 & 120 & 608 & 18 & 0.58 & 1459 & 606 & 304 \\
\hline 18 & 7.1 & 58 & 66 & 220 & 3 & 344 & 65 & 373 & 9 & 0.56 & 982 & 416 & 282 \\
\hline 19 & 7 & 76 & 97 & 312 & 7 & 373 & 118 & 571 & 16 & 0.6 & 1400 & 588 & 306 \\
\hline 20 & 7 & 76 & 119 & 360 & 7 & 355 & 192 & 654 & 21 & 0.66 & 1612 & 678 & 291 \\
\hline
\end{tabular}

\subsection{PH}

$\mathrm{PH}$ of solution is taken as negative logarithm of $\mathrm{H}_{2}$ ions for many practical practices. The $\mathrm{pH}$ of selected site lies from 6.4 to 7.2 .

\subsection{Total Dissolved Solids (TDS)}

TDS is used to determine how the ions are dispersing in the water The acceptable and permissible limit as per BIS is 500 and 2000 $\mathrm{mg} / \mathrm{L}$ respectively. Here the value ranges from 473 to $2195 \mathrm{mg} / \mathrm{L}$.

\subsection{Total Hardness}

The scale formation is caused by hardness. The acceptable and permissible limit as per BIS is 300 and $600 \mathrm{mg} / \mathrm{L}$ respectively. Here the value ranges from 185 to $970 \mathrm{mg} / \mathrm{L}$.

\subsection{Sulphate}

The solubility nature of water is determined based on the sulpate availability. The acceptable and permissible limit as per BIS is 200 and $400 \mathrm{mg} / \mathrm{L}$ respectively. Here the value ranges from 10 to $314 \mathrm{mg} / \mathrm{L}$.

\subsection{Nitrate}

Nitrogen availability is used to identify the quantity of Nitrate in water. The acceptable and permissible limit as per BIS is 45 and $100 \mathrm{mg} / \mathrm{L}$ respectively. Here the value ranges from 4 to $38 \mathrm{mg} / \mathrm{L}$.

\subsection{Total Alkalinity}

The acceptable and permissible limit of alkalinity in groundwater as per BIS is 200 and $600 \mathrm{mg} / \mathrm{L}$ respectively. Here the value of alkalinity ranges from 225 to $475 \mathrm{mg} / \mathrm{L}$.

\subsection{Chloride}

The acceptable and permissible limit of chloride in groundwater as per BIS is 250 and $1000 \mathrm{mg} / \mathrm{L}$ respectively. Here the value ranges from $121-1046 \mathrm{mg} / \mathrm{L}$.

\subsection{Fluoride}

The nature of earth crust determines the availability of fluoride in groundwater. The acceptable and permissible limit of fluoride as per BIS is 1 and $1.5 \mathrm{mg} / \mathrm{L}$ respectively. Here the value ranges from 0.4 to $1.58 \mathrm{mg} / \mathrm{L}$.

\subsection{Potassium}

Potassium occurs naturally in minerals and from soils. The acceptable and permissible limit as per BIS is 10 and $10 \mathrm{mg} / \mathrm{L}$ respectively. Here the value ranges from 0 to $28 \mathrm{mg} / \mathrm{L}$.

\subsection{Calcium}

Calcium is an important nutrient for aquatic, organism and it is commonly present in all water bodies. The acceptable and permissible limit as per BIS is 75 and $200 \mathrm{mg} / \mathrm{L}$ respectively. Here the value ranges from 36 to $148 \mathrm{mg} / \mathrm{L}$.

\subsection{Magnesium}

Magnesium is directly related to hardness. Magnesium in the groundwater samples is from 22 to $134 \mathrm{mg} / \mathrm{L}$. The BIS acceptable and permissible limit is 30 and $100 \mathrm{mg} / \mathrm{L}$ respectively.

\subsection{Sodium}

Sodium is a natural constituent of raw water, but its concentration is increased by pollution sources such as rock salt, precipitation runoff, soapy solution and detergent. Presence of high concentration gives bitter taste to water. In the present study, the sodium concentration varies from $110 \mathrm{mg} / \mathrm{L}$ to $478 \mathrm{mg} / \mathrm{L}$. Its acceptable limit as per BIS is $200 \mathrm{mg} / \mathrm{L}$.

\subsection{Bicarbonate}

The bicarbonate concentration in groundwater ranges from 275 to $580 \mathrm{mg} / \mathrm{L}$. The BIS acceptable limit is $200 \mathrm{mg} / \mathrm{L}$.

\subsection{Water Quality Index}

The WQI was calculated using the equations 1 to 4 and the results are presented below. The Table 5 shows the WQI calculation for the well no. 1 . The Table 6 shows the WQI for 20 bore well groundwater samples based on BIS acceptable limit. From the Table 5, it may be noted that the WQI was determined as 208.67, indicates the groundwater quality from the well number 1 is very poor quality. 
Table 5: WQI based on BIS Acceptable Limit

\begin{tabular}{|c|c|c|c|c|c|c|}
\hline Parameters & $\begin{array}{l}\text { Acceptable } \\
\text { Limit (si) }\end{array}$ & $\begin{array}{l}\text { Observed Values } \\
\text { (Ci) }\end{array}$ & $\begin{array}{l}\text { Weight Factor } \\
\text { (wi) }\end{array}$ & $\begin{array}{c}\text { Relative Weight Fac- } \\
\text { tor (Wi) }\end{array}$ & Quality Rating (Qi) & $\begin{array}{c}\text { Water Quality Index } \\
\text { (Si) }\end{array}$ \\
\hline $\mathrm{pH}$ & 7 & 7.1 & 5 & 0.11 & 101.43 & 11.27 \\
\hline $\mathrm{Ca}$ & 75 & 88 & 2 & 0.04 & 117.33 & 5.21 \\
\hline $\mathrm{Mg}$ & 30 & 182 & 1 & 0.02 & 606.67 & 13.48 \\
\hline $\mathrm{Na}$ & 200 & 433 & 4 & 0.09 & 216.50 & 19.24 \\
\hline $\mathrm{K}$ & 10 & 3 & 2 & 0.04 & 30.00 & 1.33 \\
\hline $\mathrm{HCO}_{3}$ & 200 & 580 & 2 & 0.04 & 290.00 & 12.89 \\
\hline $\mathrm{SO}_{4}$ & 200 & 104 & 5 & 0.11 & 52.00 & 5.78 \\
\hline $\mathrm{Cl}$ & 250 & 922 & 4 & 0.09 & 368.80 & 32.78 \\
\hline $\mathrm{NO}_{3}$ & 45 & 9 & 4 & 0.09 & 20.00 & 1.78 \\
\hline $\mathrm{F}$ & 1 & 0.61 & 2 & 0.04 & 61.00 & 2.71 \\
\hline TDS & 500 & 2032 & 5 & 0.11 & 406.40 & 45.16 \\
\hline $\mathrm{TH}$ & 300 & 970 & 5 & 0.11 & 323.33 & 35.93 \\
\hline TA & 200 & 475 & 4 & 0.09 & 237.50 & 21.11 \\
\hline & & & 45 & & & 208.67 \\
\hline
\end{tabular}

Table 6: Remarks of WQI based on BIS acceptable limit

\begin{tabular}{|c|c|c|}
\hline Wells & Water Quality Index & Remarks \\
\hline 1 & 208.67 & Very Poor \\
\hline 2 & 63.30 & Good \\
\hline 3 & 165.32 & Poor \\
\hline 4 & 145.62 & Poor \\
\hline 5 & 219.63 & Very Poor \\
\hline 6 & 198.62 & Poor \\
\hline 7 & 173.85 & Poor \\
\hline 8 & 207.62 & Very Poor \\
\hline 9 & 194.92 & Poor \\
\hline 10 & 156.00 & Poor \\
\hline 11 & 177.48 & Poor \\
\hline 12 & 207.76 & Very Poor \\
\hline 13 & 194.24 & Poor \\
\hline 14 & 173.30 & Poor \\
\hline 15 & 173.28 & Poor \\
\hline 16 & 168.84 & Poor \\
\hline 17 & 153.03 & Poor \\
\hline 18 & 109.25 & Poor \\
\hline 19 & 147.24 & Poor \\
\hline 20 & 166.3 & Poor \\
\hline
\end{tabular}

From the Table 6, it may be observed that the only well number 2 is most suitable for drinking purpose, because the well 2 was located in the upstream of the Ambattur Industrial Estate. The wells number $3,4,6,7,9,10,11$, and 14 to 20 are observed as poor quality, further, the wells number $1,5,8$, and 12 are observed as very poor quality, results groundwater from the above wells are not suitable for drinking uses.

The GIS is used to assess the groundwater quality parameters against drinking in the study area by Ambiga [1]. The groundwater quality index indicated that $82 \%$ of the groundwater samples drop within the poor type and are unsuitable for drinking purposes. The six water samples from ten villages of Koilwar block were collected and analyzed for eleven basic water quality parameters and determined WQI. WQI ranged from 40.67 to 69.59 indicated that some pre-treatments are required before consumption [2]. Physico-chemical investigations were carried out for the parameters of Temperature, anions, cations, TDS and hardness. The physico-chemical results were related to drinking water strategies of Indian Standard (IS) for its purification [3].

The twelve basic water quality parameters were considered for determining WQI and WQI ranges found between 89.21 and 660.56. The presence of high amount of iron, nitrate, TDS, hardness, bicarbonate, fluorides and manganese in the groundwater contribute the high WQI in Tumkur [4].

The ten basic water quality parameters was considered for determining WQI and the results of WQI indicated that groundwater samples ranged between 244 and 383.8 [5]

This study presented the assessment of groundwater quality in Ambattur Industrial Estate, Chennai for its suitability of drinking water using WQI. The selected paramters are $\mathrm{pH}$, TDs, $\mathrm{TH}, \mathrm{Cal}-$ cium, Magnesium, Sulphate, Nitrate, Total alkalinity, Chloride, Fluoride, Sodium, Bicarbonate and Potassium. WQI observed from those selected 20 groundwater bore wells are ranging from 63.30 to 219.63. High values of TDS and chloride are contributing high value of WQI of this study area. Similarly total hardness concentration was found to be higher in some sample station. Few sample station showed higher value of alkalinity, sodium and bicarbonate.

\section{Conclusions}

The study was conducted to assess the quality of groundwater using WQI. The groundwater samples were collected from 20 bore wells located in Ambattur Industrial Estate in Chennai city. The samples were subject to physico-chemical analysis. The WQI results showed that the water quality of bore wells around Ambattur Industrial Estate is poor for drinking purpose. Groundwater of this area requires some prior treatment before consumption for all purposes. It is recommended that groundwater quality checking would be done in terms of basic water quality parameters whenever environment change. It is also recommended to be organized some awareness programs to make them aware about the possible ill effects of ground water pollution.

\section{Acknowledgement}

The Authors express their gratitude to the Management of Vel Tech High Tech Dr.Rangarajan Dr.Sakunthala Engineering College, Avadi, Chennai, Tamil Nadu, India, for their support to complete this project successfully.

\section{References}

[1] Ambiga K, "Assessment of groundwater quality index using GIS at Tirupathi, India", International Research Journal of Engineering and Technology, Vol. 03, No. 02, 2016, 552-564.

[2] Neerja K, Rajesh Kumar S, Yadav S \& Singh RT, "Water quality index assessment of ground water in Koilwar block of Bhojpur (Bihar)", Journal of Chemical and Pharmaceutical Research, 2012, Vol. 04, No. 03, 1782-1786.

[3] Patel T, Mahour PK, Mahour R, Lautre HK \& Shah P, "Physicochemical analysis of ground water quality of Dhrol", Environmental Science: An Indian Journal, 2016, Vol. 12, No. 12, 1-7.

[4] Ramakrishnaiah CR., Sadashivaiah C \& Ranganna G, "Assessment of water quality index for the groundwater in Tumkur Taluk, Karnataka State, India", E-Journal of Chemistry, 2009, Vol. 06, No. 02, 523-530.

[5] Sirajudeen J \& Abdul Vahith R, "Applications of water quality index for groundwater quality assessment on Tamil Nadu and Pondicherry, India", Journal of Environmental Research and Development, 2014, Vol. 08 No. 03, 443-450.

[6] Sivakumar D, Thiruvengadam M, Anand R \& Ponpandian M, "Suitability of groundwater around Pallavaram, Chennai, Tami Nadu", Pollution Research EM International, 2014, Vol. 33, No. 03 , 541-546. 
[7] Sivakumar D, Kandaswamy AN, Kalpana Priya V, \& Hemalatha $\mathrm{S}$, "Suitability of groundwater in and around Tannery industrial belt", Journal of Chemical and Pharmaceutical Sciences, 2015, Vol. 08, No. 02, 292-297.

[8] Sivakumar D, Abraham Daniel Raj P, Arivoli E, \& Hemalatha M, "Groundwater Suitability for Irrigation in Pulicat Using GIS", Journal of Chemical and Pharmaceutical Sciences, 2016, Vol. 09, No. 03, 1542-1549.

[9] Sivakumar D, Lavanya Pavithra S, Vasuki K, \& Lavanya B, "Groundwater suitability for irritation around Perungalathur, Chennai, Tamil Nadu", International Journal of Applied Engineering Research (IJAER), 2015, Vol. 10, No. 53, 37-42.

[10] Sivakumar D, Keerthana B, Kirthana PC, \& Sandhiya G, "A case study of the correlation criteria of groundwater intended for water supply around Perungalathur, Chennai", International Journal of Applied Engineering Research (IJAER), 2015, Vol. 10, No. 53, 263-267 